\title{
Work Histories and Voluntary Association Memberships
}

\author{
Thomas Rotolo $^{1,3}$ and John Wilson ${ }^{2}$
}

We explore the impact of work histories on voluntary association memberships. Stable work histories are associated with more membership months over a 15-year period, in contrast to a "disorderly" sequence of jobs, which results in fewer membership months. Men's work histories affect only their job-related memberships; women's work histories affect a wider range. These results suggest that current trends in the restructuring of work toward more contingent employment will decrease rates of civic participation.

KEY WORDS: work; career; voluntary associations; social capital.

Declining membership in many voluntary associations and low voter turnout in presidential elections has raised widespread concern about the health of civil society in America. Among the many reasons cited for these trends is changing patterns of employment. For example, more and more women, traditionally the "community housekeepers" (Daniels, 1988), are working full-time, regardless of whether they have small children. This, in turn, reduces the amount of free time families have to devote to community organizations especially if both spouses are working (Reich, 2000:118).

Americans are apparently becoming too harried to be joiners. However, the evidence that increasing work time is eroding community life is mixed at best. It is true that the number of hours people spend in community associations is affected by how long they work, but having no job at all discourages social participation rather than making it easier (Brown, 1999; Freeman, 1997; Putnam, 2000:194). Perhaps time is not the issue here. What is more

\footnotetext{
${ }^{1}$ Department of Sociology, Washington State University, Pullman, Washington 99164.

${ }^{2}$ Department of Sociology, Duke University, Durham, North Carolina.

${ }^{3}$ To whom correspondence should be addressed; e-mail: rotolo@wsu.edu.
} 
important about a job is the way it locates us within a larger social structure. Holding a job is one way of being integrated into one's community. Holding a steady job promises to accomplish this function even more effectively. As the economy changes, occupations are redefined, new work arrangements devised, and old work practices abandoned. These changes inevitably restructure the relationship between work and nonwork spheres. The threat to civil society from changes in the economy comes not so much from new demands on our time, but from the restructuring of our jobs. The world of paid employment is being transformed as the old "contract" between labor and management breaks down, to be replaced by new, more competitive, and more contingent employment agreements. In this paper we attempt to show that new forms of work have the potential to undermine civil society by making it more difficult for us to become engaged in our community.

\section{WORK, WORK HISTORIES, AND SOCIAL PARTICIPATION}

It is customary when linking work and social participation to invoke the idea of occupational status. Over four decades ago, Kahl (1957:147) noted, "Every study of formal associations ... shows the same trend: people of higher prestige status belong to more voluntary formal associations than people of lower status." There are several ways to account for this association. To some degree it is spurious because education is positively associated with both occupational prestige and joining. But higher prestige jobs do teach more "civic skills," thus enabling more civic participation (Verba et al., 1995). Many companies expect their managers to become involved in community affairs (Hougland and Shepard, 1985:66; Schwirian and Helfrich, 1988:65) as part of their corporate outreach program. Many small businesses use community-based associations to build contacts. Many professionals belong to associations that encourage, to the point of an ethical obligation, performing some kind of service work in the community. Undoubtedly, many managers and professionals reap the benefits of these memberships in the form of human and social capital they can use to build their careers. But it is unlikely that voluntary association memberships cause careers. The evidence suggests, rather, that careers cause memberships (Wilson and Musick, 1997).

This way of thinking about jobs encourages us to view them as statuses or positions with costs and benefits attached to them. But each job we hold at any given time is part of a longer trajectory of jobs we will perform until we retire. As Pavalko et al. (1993:364). note "Few people have jobs that remain static throughout their work lives; many change jobs several times over their careers, others may move in and out of the labor 
force, and even those who remain in the same job for most or all of their work life are likely to experience changes in the demands and rewards of that work." Each of our jobs is one step in a "career pathway" which describes the structure of our working life rather than measuring its state at any given moment. The "process of identifying typical career pathways is analogous to that of using 'structural equivalence' as a basis for grouping actors in network analysis" (Han and Moen, 1999:203). It locates jobs in time rather than space. To think about jobs in this way, we must shift from cross-sectional comparisons between individuals and their jobs to comparisons between patterns of events (i.e., career pathways) over the life course. We must treat work as a process rather than a position. Examining work histories makes it possible to associate people on the basis of the similarity of their careers rather than the similarity of their current jobs. Current education, current income, even current job, are less important than our history of employment.

Why should the study of work histories be relevant to the study of social participation? The answer lies in Durkheim's theory of the integrative role of occupational groups (Durkheim, 1933:26-27) and Wilensky's important elaboration of this theory (Wilensky, 1961). Durkheim believed that in modern society the workplace would draw people into the mainstream of social life and thus perform an integrative role. Wilensky (1961:522) shared the view that participation in community life is a "natural extension of participation in the labor market," but added a crucial dimension: the "vitality of social participation ... and the strength of attachment to community ... are in part a function of cumulative experience in the economic system." He believed that social integration depended on having an "orderly" and "pleasant" work history. Only a work history with these characteristics would bond people to their neighborhoods, give them a stake in the welfare of their community, and provide them with an incentive to become active in it. In contrast, people would have the least incentive to become active in their communities if their work life had been "disorderly" and the jobs unpleasant.

Wilensky's theory is highly relevant to the current debate about the changing patterns of work because work histories are being redrawn. The new economy is not only altering the distribution of jobs, it is rewriting work histories. As a result of increasing "nonstandard work arrangements," such as part-time jobs, temporary employment, and subcontracting (Kalleberg, 2000), "[s]teady work-a predictable level of pay from year to year-has disappeared for all but a handful of working people" (Reich, 2000:98). Fifty years ago more than a third of blue-collar workers belonged to a trade union, and agreements between labor and management set wage and benefit levels throughout industry. Jobs were relatively secure for the life of the contract. 
The work lives of the growing phalanx of white-collar employees were even more orderly and predictable. Since that time, however, this "contract" between labor and management has largely broken down. More and more people have "disorderly" work lives, moving from job to job, with little sense of continuity between them.

\section{CONCEPTUALIZING WORK HISTORIES}

Although consideration of work in terms of a career is by no means novel, attempts by sociologists to conceptualize and measure work histories in their entirety are relatively rare (Han and Moen, 1999; Pavalko et al., 1993). Crucial to Wilensky's way of thinking about a work history is its degree of "orderliness." His conceptualization is quite complicated because it calls for the combination of three criteria when considering the sequence of jobs people hold over their lives: (1) whether or not the jobs are "functionally related," or require the same job skills; (2) whether job changes follow some structured sequence of progression; and (3) whether job changes take people from one occupational stratum to another. Combining these criteria yields the following types of work history (Wilensky, 1961:521):

- Orderly vertical. The individual moves between jobs that are functionally related to each other (i.e., skills gained in one can be used in the others); jobs are hierarchically ordered (i.e., there is a sense of "moving up the ranks"); and the mobility entails movement across occupational strata (e.g., from white collar to manager).

- Orderly horizontal. The work history is characterized by job changes that are functionally related in that skills learned in one job can be used in another; jobs are arranged in a hierarchy of status, but the progression does not take the worker across occupational strata.

- Disorderly horizontal. The jobs are not functionally related, nor are they hierarchically ordered, but all work is performed in the same occupational stratum.

- Disorderly vertical. Successive jobs are not functionally related, nor is there any progression through the ranks implied by the sequence; however, the jobs do cut across occupational strata.

- One job for the entire work history. No job changes occur over the observation period.

The first type of work history, orderly vertical, closely resembles the archetypal "career," as "a succession of related jobs, arranged in hierarchy of 
prestige, through which persons move in an ordered ... sequence" (Wilensky, 1961:523). It usually culminates in a management or professional position. Thus, a person who works for a retail chain, such as The Gap, might begin as a "sales associate," obtain promotion to the position of assistant manager and then manager in the same store, and eventually move up into middle or regional management in that or another retail company, overseeing a number of stores.

The other type of orderly work history, orderly horizontal, also describes a progression but it takes place within an occupational stratum. A person who takes a job as an assistant professor in a university illustrates this case. She is immediately classified as a "professional." Although her career might see her rise through the ranks to full professor, she does not leave that stratum.

A work history is categorized as "disorderly" if consecutive jobs are neither functionally related nor hierarchically ordered. Wilensky further differentiates between disorderly work histories in which some occupational mobility occurs (disorderly vertical) and job changes where no mobility occurs (disorderly horizontal). An example of a disorderly vertical work history is that of the construction worker who moves to a job as sales associate in an auto-parts store before becoming assistant manager in a furniture warehouse. A person who takes a number of different midlevel sales jobs (tools, cemetery plots, cosmetics, etc.) would exhibit a disorderly horizontal work history. ${ }^{4}$ The final category of work history identifies individuals who keep the same job.

Wilensky's (1961:539) "guiding hypothesis" is that work histories make a difference to community participation: "[C]haotic experience in the economic order fosters a retreat from both work and the larger communal life." In his own study, Wilensky used data gathered from 678 male respondents. Their median age was 39 years. They were almost evenly divided between white-collar and blue-collar workers. He sorted their work histories into orderly vertical (17\%), orderly horizontal (13\%), disorderly horizontal (5\%), disorderly vertical (29\%), "borderline orderly vertical" (33\%), and a small remainder with one job only (3\%). Men with orderly work histories reported more associational memberships, spent more time at associational meetings, attended meetings more frequently, and belonged to a wider variety of associations.

\footnotetext{
${ }^{4}$ Note that because the worker remains in the same occupational stratum, a disorderly horizontal work history may involve jobs with some degree of functional relation. For instance, a series of different jobs in the broader category of "sales" occupations may be functionally related, to some extent, in that sales techniques learned in one job might be transferable to others. However, the product lines, work environments, and other distinguishing features of the jobs are likely to differ.
} 


\section{STUDY DESIGN}

Our goal is to replicate Wilensky's study, using more recent data. As with most replications, our design includes some inevitable differences, but its logic and reasoning parallel the original. First, we do not have complete work histories on our respondents. Instead, we gathered work histories over a 15-year period. We believe this is long enough for the structure of work histories to exhibit effects, but inevitably a much higher percentage of our respondents will have held the same job than was the case with Wilensky. For us, people who have kept the same job represent exactly the kind of "steady" and "unchaotic" work life Wilensky believed would encourage civic participation. In all likelihood, people who have the same job for 15 years live in the same neighborhood and perhaps even in the same house. We call these people "stayers" and use them as our baseline category, against which all other work histories are compared. We retain the logic of Wilensky's argument by hypothesizing that respondents with disorderly work histories will have lower participation rates than the stayers, while those who experience orderly changes will be somewhere in between the other two categories of work history.

A second difference between our study and Wilensky's is that our sample includes women. The absence of women from a study of the relation between work and leisure was quite typical at the time Wilensky gathered his data. He does not speculate on how his results might be affected by the inclusion of women. Gender determines who does what kind of work, how work roles are defined, and how they relate to other social roles. There is good reason to believe that Wilensky's findings cannot be generalized to women. Men and women differ in responsibilities for household activities, especially household chores and child-care (South and Spitze, 1994). Because conflict between work and family roles is more likely among women, we expect the negative effect of disorderliness to be weaker for women. This is not to say that women are absent from the world of voluntary associations but that orderliness of work histories makes less difference to the likelihood of their being active there than it does for men (Booth, 1972:187). Some evidence suggests that women's association with voluntarism is less influenced by their work than is men's. Booth (1972:187) finds that "women in all strata show stable patterns of participation throughout their life, whatever their condition." As far as the life course is concerned, the sequence of family events is probably more important to women than the sequence of work events (McPherson and Smith-Lovin, 1982:893).

Hypothesis 1. The negative effect of disorderly work histories and the positive effect of stable work histories on volunteering are stronger for men than women 
A third difference between our study and Wilensky's is that we examine the effect of work histories on different types of association membership. Wilensky is well aware that voluntary associations differ in kind, but he seems to assume that work histories would have the same effect on membership in all types. However, if the tie between work history and membership is largely instrumental, work histories should have a stronger effect on work-related memberships than on other types. We intend to examine this possibility.

Hypothesis 2. The negative effect of disorderly work histories and the positive effect of stable work histories on volunteering are stronger for workrelated memberships than for other types of memberships.

\section{DATA}

Data come from the Ten Towns Study, a probability sample of 1050 individuals from 10 communities in Nebraska, conducted in the summer of 1989 (see McPherson and Rotolo, 1996; Munch et al., 1998; Rotolo, 2000). In addition to the standard set of social and economic items, respondents were asked about the timing of voluntary association membership activities, their employment history, and life course events such as marriage and the birth of children. The survey implemented the life-history calendar method to help respondents recall events as far back as August 1974 (using the Watergate hearings as an anchoring event), or when the respondent turned 16 years of age.

The job history data we use in this study were obtained through a combination of closed- and open-ended questions. First, respondents were asked, "Now we would like to know something about your job history. Going back to (August 1974/when you were 16 years old), were you working full-time, working part-time, unemployed, in school, retired, keeping house, or something else?" Respondents who were working were asked to identify the kind of work they did; an open-ended question obtained job title, duties, industry, and other job characteristics. Next, respondents were asked, "What did you do after that? Were you working full time, part time, unemployed, in school, retired, keeping house, or something else?" Clarification was provided for those respondents who were employed full-time in their initially reported job; respondents working full-time received the additional prompt: "By this I mean either not working full time or moving to a job with another employer." If the respondent experienced a change in employment, the survey collected information about the next job, using the open-ended question (and/or work status change, if applicable), and the timing of the transition (reported to the month). The survey continued to ask respondents about their employment history until they reached their current job in the summer 
of 1989. This approach allows us to track respondents over the 15-year period as they change work statuses (e.g., full-time employee to retired), and as they move from job to job (e.g., a grocery store stocker might become manager of the store). Information on all jobs held across the 15-year series is used for our analysis of cumulative membership.

Other researchers have used these same data to explore the connection between work and social participation (e.g., Drobnic (1992) explores the relationship between careers and the joining rate of voluntary associations). However, Wilensky's ideas have never been explicitly addressed and tested using these data. Further, to the best of our knowledge, published research has not used the open-ended questions that tap into characteristics of the job (one exception is Rotolo and Wharton, 2003).

Respondents were also asked to recall information about their voluntary association memberships between 1974, or from the time the respondent was 16 years old, and 1989. The survey asked,

\footnotetext{
Some people are members of different kinds of groups, while others are not members of any. Now, I would like to ask you some questions about the organizations that you may belong to now or you used to belong to in the past. Again, please start with August, 1974 when Richard Nixon resigned, or if you were under age 16 then, start thinking from when you were 16 years old.
}

First, respondents were read a list of 17 group types, and asked if they belonged to any of the specific group types over the period. If the respondent indicated belonging to a specific group type, information on current membership status (Are you still a member of this group?), and timing of the membership was collected (e.g., What year/month did you join the organization? What year/month did you leave the organization?). If a respondent was unable to report an exact month, the mean month was substituted (equal to 6). This imputation makes no substantive difference in any results reported here. We do not use all 17 group types in our analysis because the cell sizes would be too small. We group the types into five categories of association: professional, union- and farm-related, civic, fraternal, and expressive (expressive voluntary groups, such as neighborhood associations or educational organizations, perform activities related to socialization, communal cohesion, and social integration).

Our sample for the analyses presented here consists of 686 individuals. The reduction in sample size from the original survey is primarily a consequence of our focus on employment. Respondents were asked to detail their employment histories over a 15-year period (1974-89). As might be expected, not all respondents were able or willing to provide detailed information on their work status and jobs over the period. Because our analysis strategy requires complete information on job histories across the entire 15 -year period, we did not include respondents with any missing data on their work 
histories or detailed job characteristics. Preliminary analyses failed to reveal any systematic differences between those with missing data on work histories and those included in our analyses. However, we suspect that respondents with missing data are most likely to have experienced relatively turbulent job histories-making the exact timing of transitions difficult to remember. While the exclusion may limit the extent to which we can generalize our findings, our remaining sample does exhibit substantial variation in work history and membership history (e.g., sufficient numbers of our respondents experience both turbulent and stable job histories). Additionally, using data from the U.S. Census (1990), we compared the occupational distribution of our sample of workers to the occupational distributions of workers in Nebraska and the United States. Our sample is comparable to these populations, although the proportion of farm workers in Nebraska is higher than in the general population. This difference is reflected in our data. Given the paucity of research in this area using longitudinal data, this study offers an original perspective on the interplay between work histories and volunteering.

\section{Variables}

\section{Dependent Variable: Voluntary Association Membership Months}

As discussed above, each respondent reported starting and ending times for all voluntary association memberships. Using this information, we calculated the total number of months a respondent reported membership in all voluntary organizations. ${ }^{5}$ We only counted membership months that fell between our 15-year observation period, corresponding to August 1974 or when the respondent turned 16 and the time of survey administration in the summer of 1989. We employ ordinary least squares regression to assess the impact of work history on total months of membership. ${ }^{6}$

\section{Independent Variable: Work Histories}

Using Wilensky's typology as a guide, we created a series of five mutually exclusive and exhaustive dummy variables to represent respondents'

\footnotetext{
${ }^{5} \mathrm{We}$ also explored a measure of level of participation, with data on the number of hours spent per month in activities connected with each organization. The results from analyses of total participation in voluntary group activities were very similar to those using the total number of months reported membership.

${ }^{6}$ We conducted analyses with Poisson regression models, corrected for overdispersion, and the results did not differ substantively from the analyses with ordinary least squares regression. For the ease of interpretation, we report results from OLS models in all tables.
} 
work histories. We assess each respondent's work history on two dimensions. First, if a respondent's work history involves a series of jobs that are similar in nature (that is, the jobs involve similar work tasks) then the history is orderly; jobs that are not task related are disorderly. Second, we identify a work history as vertical if it contains a series of jobs that imply some degree of occupational mobility; work histories that do not exhibit evidence of mobility across occupational categories are coded as horizontal. Thus, for respondents reporting at least one job change, we use a four-category scheme (with hypothetical examples following in parentheses):

1. orderly vertical (secretary becomes an administrative assistant);

2. orderly horizontal (person moves from carpenter's apprentice to journeyman to foreman in a construction firm);

3. disorderly vertical (e.g., retail sales clerk becomes a high school teacher); and

4. disorderly horizontal (toll-booth attendant becomes a security guard).

Our coding procedure for identifying disorderly vertical work histories was relatively conservative. If a series of jobs involved a move from one broad occupational category to another, that work history was coded as disorderly vertical because there was some evidence of a change in job prestige.

Like Wilensky, we include a category we call stayers. These are people who remain in the same job across the entire series. Because our time span is so much shorter than Wilensky's we have a much larger number of respondents who held the same job throughout the measurement period than he did. We use the stayer work history as the omitted category in the analysis.

Given Wilensky's coding scheme and the adaptation of it we use here, it is quite possible that, over an individual's entire work history, a sequence of job changes might fall into more than one category. One sequence of moves might be orderly and another disorderly. The relatively brief time span with which we deal reduces the possibility of this problem occurring. Nevertheless, we decided that, if at least half the months covered in a work history consisted of jobs that were orderly, the history would be coded orderly; otherwise it would be coded disorderly. This coding remains consistent with Wilensky's original typology, which similarly considered the proportion of time individuals spent in work history categories.

\section{Control Variables}

We used a number of control variables in the analysis of work histories and membership months because we were concerned that they might be determining activity in both domains and thus render any uncovered 
relationship spurious. We include age in years at time of survey administration in our models because respondents of different ages are likely to display different work histories and membership patterns. We control for marital status because this might affect both employment patterns and membership activity. We construct an indicator for marital status by calculating the percentage of months during the 15 -year observation period that the respondent was married. The presence of children may influence both career and membership in voluntary associations. In particular, individuals with children of school age may be more likely to report membership in voluntary groups than those without children in this age range (Knoke and Thomson, 1977; Rotolo, 2000). Therefore, we include a parental status variable that measures the percentage of the observation period in which the respondent reports having at least one child between the age of 5 and 17 years (i.e., school-age children) in the household. Finally, we wanted to be confident that any association between work history and membership history was actually the product of socioeconomic status at the beginning of the study period. For example, college graduates might be more likely to have "careers" and more likely to be joiners. Respondents were asked to report their highest level of education (in years); we include education as a control in all models.

\section{RESULTS}

We set the stage for our multivariate analyses by providing some basic, descriptive statistics, by type of association. Table I shows that respondents report the most membership months in expressive, followed by professional

Table I. Descriptive Statistics for Selected Dependent and Independent Variables

\begin{tabular}{|c|c|c|c|c|}
\hline & \multicolumn{2}{|c|}{ Males $(n=317)$} & \multicolumn{2}{|c|}{ Females $(n=369)$} \\
\hline & $M$ & SD & $M$ & SD \\
\hline \multicolumn{5}{|l|}{ Membership variables } \\
\hline Total membership months & 272.60 & 380.89 & 258.87 & 282.57 \\
\hline Professional membership months & $56.82^{a}$ & 152.96 & 22.51 & 107.05 \\
\hline Expressive membership months & $126.82^{a}$ & 193.25 & 171.54 & 199.03 \\
\hline Civic membership months & $28.28^{a}$ & 68.02 & 9.27 & 36.97 \\
\hline Fraternal membership months & $31.64^{a}$ & 93.02 & 20.13 & 65.22 \\
\hline Union/farm membership months & $16.86^{a}$ & 64.28 & 6.19 & 30.40 \\
\hline \multicolumn{5}{|l|}{ Work history variables } \\
\hline Orderly horizontal & $0.12^{a}$ & 0.33 & 0.19 & 0.39 \\
\hline Orderly vertical & 0.06 & 0.22 & 0.05 & 0.19 \\
\hline Disorderly horizontal & 0.06 & 0.24 & 0.04 & 0.20 \\
\hline Disorderly vertical & 0.30 & 0.46 & 0.30 & 0.46 \\
\hline Stayers & 0.46 & 0.50 & 0.42 & 0.50 \\
\hline
\end{tabular}

${ }^{a}$ The male mean is significantly different from the female mean $(p<0.05$, twotailed tests). 
and fraternal associations. There are no gender differences in overall membership months, but men and women are drawn to different types of activities. Women participate more than men in expressive associations, but less than men in all other types of organization. This gender difference is commonly found in voluntary association research (Rotolo, 2000:1140).

The lower half of Table I shows the distribution of work historiesour primary independent variable — by gender. By far the largest category is Stayers, those who had the same job throughout the study period. This distribution is almost opposite that found by Wilensky, but it is to be expected, given the much shorter duration of observation in these data. Disorderly Vertical is the next largest category. In this group, job changes cut across occupational strata, but are not functionally related. Women are more likely than men to report Orderly Horizontal work histories; they move between jobs that are functionally related (the tasks are similar) but do not change their rank. The proportion of respondents reporting Orderly Vertical work histories, the pattern most closely resembling career, is small in this sample, as it was in Wilensky's.

Table II presents the results from our least squares regression analyses of total months of membership. Column 1 displays the results for men and column 2 provides the estimates for women. We test for the statistical significance of the gender differences observed. The category against which all other work histories are compared is Stayers. Our hypothesis is that both men and women will report more membership months if they had the same job over the observation period but the positive effect of job stability will be stronger for men than women.

Table II. Ordinary Least Squares Regression Results for Total Membership Months Reported Between 1974 and 1989, by Sex

\begin{tabular}{lcc}
\hline & Model 1 males & Model 2 females \\
\hline Intercept & $-714.491^{* *}(131.698)$ & $-513.199^{* *}(121.027)$ \\
Work History measures & & \\
(omitted category: stayers) & $-5.986(60.135)$ & $-94.539^{*}(72.299)$ \\
Orderly horizontal & $-117.085(87.277)$ & $34.408(69.902)$ \\
Orderly vertical & $105.393(79.943)$ & $-124.773^{\dagger}(90.945)$ \\
Disorderly horizontal & $-77.082^{\dagger}(45.377)$ & $-110.574^{* *}(32.341)$ \\
Disorderly vertical & & \\
Control variables & $-6.786^{* *}(1.578)$ & $5.143^{* *}(0.866)$ \\
Age & $172.54^{*}(69.009)$ & $141.722^{* *}(39.969)$ \\
Proportion months married & $59.013(65.072)$ & $4.800(43.658)$ \\
Proportion months w/ child & $44.357^{* *}(7.149)$ & $37.354^{* *}(6.099)$ \\
Education & 0.282 & 0.255 \\
$R^{2}$ &
\end{tabular}

Note. Coefficients are OLS regression estimates; standard errors are in parentheses. ${ }^{\dagger} p<0.10 ;{ }^{*} p<0.05 ;{ }^{* *} p<0.01$ (two-tailed tests). 
The results shown in Table II provide only partial support for this hypothesis. Among both men and women, the Disorderly Vertical category reports fewer membership months than the Stayers category. These categories represent the extreme ends of our continuum of work histories. However, the results otherwise fail to support Hypothesis 1. In the male model no other work history category was significantly different from the Stayers category. In the female model work histories do seem to make more difference. Including work history dummy variables in the model for women has a significant effect on total membership months reported $(F(4,369)=3.83, p<0.01)$. The coefficients display the anticipated difference between orderly and disorderly histories. However, statistical tests revealed that the gender differences in the effect of work histories were not significant. We should therefore treat with caution these findings concerning the moderating effect of gender. Only replication of this study with a larger sample and over a longer time period could determine whether these are probabilities or merely tendencies. As expected, education and proportion of months spent married are positively related to membership months for both males and females. We find different effects of age on membership months, by sex: older males accumulate fewer membership months than younger males, while older females report more membership months than younger females.

To test our second hypothesis, we estimate the effect of work histories on five different categories of organization: professional, union- and farmrelated, civic, fraternal, and expressive. In this case, we calculated the total number of months that respondents reported membership in each of these organization types. We predicted that the effect of work history on membership months would vary by type of membership. To maintain continuity with our main analysis, we estimate separate models for men and women. We do not report the results from these models in full here because only one key difference emerged. We discovered that the effect of work history on men's membership months is entirely confined to the "union and farm" category. The coefficients in Table II suggest that, when all association membership months are aggregated, only men who recorded disorderly vertical histories differ from Stayers. Our test of the second hypothesis showed that, in the case of unions and farm organizations only, men who recorded orderly vertical and disorderly vertical histories also reported fewer membership months than Stayers. In other words, work history does a better job of explaining variation in membership months in a specific type of association than it does for membership months treated as a whole-at least for the men. Among women, we found precisely the opposite. Belonging to union and farm organizations was the only category of membership not affected by work history. We therefore find support for Hypothesis 2, but it is confined to men. 


\section{DISCUSSION}

Both Wilensky's study and our own make comparisons between different work histories to ascertain their impact on social participation. Wilensky draws on Durkheimian theory to predict that social integration strengthens attachment to community. Specifically, he predicts that people with more orderly and "progressive" work histories will participate more in the associational life of their communities. We base our analysis on the assumption that stable work histories encourage the most civic participation. We found that, for both men and women, having the same job means the same thing as having an orderly vertical work history as far as membership months is concerned. Among the men, only disorderly vertical histories proved to be negative; among the women, all three categories other than orderly vertical reported fewer membership months than Stayers. This suggests that women are more affected by work histories than men. However, because statistical tests did not find these gender differences to be significant, we can only speak of tendencies at this time. In summary, the kind of job history that involves two kinds of change-between occupational strata and between different jobs requiring different tasks-is associated with the lowest level of social participation. This result gives some support to the argument that work arrangements that break down the traditional "job-for-life" pattern in the interest of economic efficiency will impose a cost in the form of weaker attachment to community and support for secondary institutions.

Our test of Hypothesis 2 suggests that the connection between men's civic participation and work history is entirely instrumental. Men who held the same job throughout the 15 -year period reported more months of membership in a union or farm organizations than those with other kinds of work history. In the case of women, union/farm membership months are not affected at all. This is probably because they are less likely to have jobs that are unionized. They are also less likely to be involved in farm-related work. If Wilensky's theory that "continuous" and "pleasant" work histories increase attachment to community and organizational membership is valid, it would seem to apply more to women than to men, a population excluded from his own study. Men's "attachment" is confined entirely to associations connected to their jobs.

One limitation of our study relates to our inability to fully replicate Wilensky's study. We lack the detailed job histories necessary to reproduce exactly the categories of work history used in his study, although we believe our breakdown remains true to the spirit and theoretical intention of his original typology. More important, Wilensky was able to ask about the individual's entire work history up to the interview time, whereas our data limit us to a 15 -year window in people's lives. No doubt we miss much of 
the variation captured by Wilensky. On the other hand, a study that does not track people throughout their lives, relying instead on respondent recall of job and membership information over long periods of time, can be very unreliable. The 15-year span used in the Ten Towns Study was considered "the best trade off between the average length of membership spells and the ability of respondents to recall membership information" (McPherson et al., 1992:160). The observed variation in respondents' work histories and the significant relationship between this variation and membership levels suggest that future research must remain aware that the job at any point in time is only part of a broader, "cumulative experience in the economic system" (Wilensky, 1961:522).

\section{CONCLUSION}

It is ironic that Wilensky (1961:539) would conclude his essay on the negative effect of "chaotic" work histories on social participation by speculating that "[i]n so far as job patterns in modern economies become more orderly and more of the population achieves the position of the young, highincome, 'some college' men of the middle mass, participation in community life is likely to increase, whatever its quality." He seemed to anticipate a future in which an increasing proportion of the population would have jobs that resembled those of the "organization man" described by William $\mathrm{H}$. Whyte. Such a society would have very high rates of social participation because people would have stable and secure jobs. As it happens, precisely the opposite has occurred. Not only has the market for labor been transformed; the supply of "social capital" appears to be dwindling.

The subject of employment has featured prominently in the current debate over the health of civil society but only as a constraint on the time people have available for social participation. This study has focused on what we regard as more important aspects of people's jobs and their impact on levels of social participation. Although the pattern of association we uncovered was not strong, we did uncover negative effects of disorderly work patterns. Our results have clear implications for the debate on how to maintain a vibrant civil society. Weaken the ties people have to the work world, and you run the risk of weakening attachment to civil society. Shift from a labor economy of job security and job continuity to a labor economy of contingent jobs, and attendance at meetings and volunteering are likely to decline.

We encourage researchers to look beyond simple correlations between voluntary association memberships and work status, or some other indicator of "busyness," such as work hours, or leisure time. As life course research tells 
us, "Single events . . . cannot be adequately understood in isolation. Rather, life events ... must be studies as part of a life trajectory in which later outcomes are partly consequences of earlier conditions, events and experiences" (Mayer and Tuma, 1990:7). The results reported here indicate the need to pay more attention to changes in the kind of work lives people have experienced as a possible explanation for the weakening of attachment to communities and the well-publicized decline of social capital.

\section{REFERENCES}

\section{Booth, Alan}

1972 "Sex and social participation." American Sociological Review 37:183-193.

\section{Brown, Eleanor}

1999 "The scope of volunteering and public service." Law and Contemporary Problems 62:17-42.

Daniels, Arlene Kaplan

1988 Invisible Careers: Women Civic Leaders From the Volunteer World. Chicago: University of Chicago Press.

Drobnic, Sonja

1992 "Firms and voluntary associations: A study in organizational careers." Unpublished PhD dissertation, Department of Sociology, Cornell University.

Durkheim, Emile

1933 Division of Labor in Society. Glencoe, IL: Free Press.

Freeman, Richard B.

1997 "Working for Nothing: The Supply of Volunteer Labor." Journal of Labor Economics 15:S140-S166.

Han, Shin-Kap, and Phyllis Moen

1999 "Clocking out: Temporal patterns of retirement." American Journal of Sociology 105:191-236.

Hougland, James G., Jr., and Jon M. Shepard

1985 "Voluntarism and the Manager: The Impacts of Structural Pressure and Personal Interest on Community Participation." Journal of Voluntary Action

Kahl, Joseph Research 14:65-78.

1957 The American Class Structure. New York: Rinehart.

\section{Kalleberg, Arne}

2000 "Nonstandard employment relations: Part-time, temporary, and contract work." Annual Review of Sociology 26:341-365.
Knoke, David, and Randall Thompson

1977 "Voluntary association membership trends and the family life cycle." Social Forces 56:48-65.

Mayer, Karl Ulrich, and Nancy Brandon Tuma 1990 "Life course research and event history analysis: An overview." In Karl Ulrich Mayer and Nancy Brandon Tuma (eds.), Event History Analysis in Life Course Research: 3-20. Madison: The University of Wisconsin Press.

McPherson, J. Miller, and Lynn Smith-Lovin

1982 "Women and voluntary organization size." American Journal of Sociology 87:883-904.

McPherson, J. Miller, Pamela A. Popielarz, and Sonja Drobnic

1992 "Social networks and organizational dynamics." American Sociological Review 57:153-181.

McPherson, J. Miller, and Thomas Rotolo

1996 "Diversity and change in voluntary groups." American Sociological Review 61:179-202.

Munch, Allison J., J. Miller McPherson, and Lynn Smith-Lovin

1998 "Gender, children, and social contact: The effects of childrearing on men and women." American Sociological Review 62:509-520.

Pavalko, Eliza K., Glen Elder Jr., and Elizabeth Clipp

1993 "Worklives and longevity: Insights from a life course perspective." Journal of Health and Social Behavior 34:363380.

Putnam, Robert D.

2000 Bowling Alone: The Collapse and Revival of American Community. New York: Simon and Schuster. 
Reich, Robert D.

2000 Future of Success. New York: Alfred Knopf.

\section{Rotolo, Thomas}

2000 "A time to join, a time to quit: The influence of life cycle transitions on voluntary association memberships." Social Forces 78:1133-1161.

Rotolo, Thomas, and Amy Wharton

2003 "Living across institutions: Exploring sex-based homophily in occupations and voluntary groups." Sociological Perspectives 46:59-82.

Schwirian, Kent, and Margaret L. Helfrich

1988 "Economic role and community involvement of business executives." Sociological Quarterly 9:64-72.
South, Scott, and Glenna Spitze

1994 "Housework in marital and nonmarital households." American Sociological Review 59:327-347.

Verba, Sidney, Kay Lehman Schlozman, and Henry Brady

1995 Voice and Equality. Cambridge, MA: Harvard University Press.

Wilensky, Harold L.

1961 "Orderly careers and social participation: The impact of work history on social integration in the middle mass." American Sociological Review 26:521-539.

Wilson, John, and Marc Musick

1997 "Work and volunteering: The long arm of the job." Social Forces 76:251-272. 